EGU2020-3436

https://doi.org/10.5194/egusphere-egu2020-3436

EGU General Assembly 2020

(c) Author(s) 2021. This work is distributed under

the Creative Commons Attribution 4.0 License.

\title{
Combined application of induced MAP (Magnesium Ammonium Phosphate) precipitation and adsorption through natural zeolites for reducing NH4+ and PO43- in swine wastewaters
}

Nicola Tescaro, Giulio Galamini, Giacomo Ferretti, Barbara Faccini, Negar Eftekhari, and Massimo Coltorti

University of Ferrara, Department of Physics and Earth Science

Combined application of induced MAP (Magnesium Ammonium Phosphate) precipitation and adsorption through natural zeolites for reducing $\mathrm{NH}_{4}{ }^{+}$and $\mathrm{PO}_{4}{ }^{3-}$ in swine wastewaters

Nicola Tescaro*1, Giulio Galamini1, Giacomo Ferretti1, Barbara Faccini, Negar Eftekhari, Massimo Coltorti

* Corresponding author

1) Department of Physics and Earth Science, University of Ferrara, Ferrara Via Saragat 1 44122, Italy.

Modern agriculture, in response to the constantly increasing need of high crop production, requires application of high levels of $\mathrm{N}$ and $\mathrm{P}$ fertilizers to soil. These substances are mainly composed by nutrients such as $\mathrm{NH}_{4}^{+}$and $\mathrm{PO}_{4}{ }^{3-}$ and are often applied in strong excess in order to assure high crop yield. The nutrients applied through fertilizers and not exploited by crops (estimated on average around 50\%) can considerably impairs environmental quality through nitrogen losses in atmosphere $\left(\mathrm{N}_{2} \mathrm{O}, \mathrm{NO}_{x}, \mathrm{NH}_{3}\right)$ and eutrophication of water bodies.

In this work, a new method for reducing $\mathrm{NH}_{4}^{+}$and $\mathrm{PO}_{4}{ }^{3-}$ in swine wastewaters (commonly used as organic fertilizer) was studied. The aim is to reduce their environmental impact and concomitantly create a new slow-release fertilizer.

Two techniques have been combined: the induced MAP precipitation (magnesium ammonium phosphate) and natural zeolite ammonium adsorption for removing the $\mathrm{NH}_{4}{ }^{+}$excess that generally remains in solution after MAP precipitation. Given the complexity of working with real wastewaters, in this preliminary phase a synthetic analogue was used in order to better evaluate the efficiency of this method. Two synthetic wastewaters with different $\mathrm{Mg}^{2+}: \mathrm{NH}_{4}{ }^{+}: \mathrm{PO}_{4}{ }^{3-}$ molar ratio were tested: MR1 (1:1,5:1) and MR2 (2:1:1), which according to the literature give the best reductions of $\mathrm{NH}_{4}^{+}$and $\mathrm{PO}_{4}^{3-}$. Since swine wastewater are naturally rich of both $\mathrm{NH}_{4}^{+}$and $\mathrm{K}^{+}$, isotherm studies were conducted on natural zeolites for evaluating their adsorption capacity of 
$\mathrm{NH}_{4}^{+}$under different levels of $\mathrm{K}^{+}$competition. Results showed that the potential in $\mathrm{NH}_{4}^{+}$ adsorption decreased while competition with $\mathrm{K}^{+}$increased. The combination of MAP precipitation and $\mathrm{NH}_{4}{ }^{+}$adsorption by natural zeolite has been tested in 2 ways: 1) zeolite was added before inducing MAP precipitation 2) zeolite was added after inducing MAP precipitation. These two treatments were compared to a blank in which only MAP precipitation technique was used.

The amount of $\mathrm{NH}_{4}{ }^{+}$and $\mathrm{PO}_{4}{ }^{+}$was monitored in various steps during the experiments as well as SEM observations were conducted on precipitated obtained. Results showed that adding zeolites before MAP precipitation induce a variation in the $\mathrm{Mg}^{2+}: \mathrm{NH}_{4}{ }^{+}: \mathrm{PO}_{4}{ }^{3-}$ ratio due to cation exchange processes before MAP precipitation which introduce interfering ions such as $\mathrm{Ca}^{2+}$ favoring calcium phosphates precipitation instead of MAP. The best test conditions, which produced the $75,1 \%$ of $\mathrm{NH}_{4}^{+}$and $99,9 \%$ of $\mathrm{PO}_{4}{ }^{3-}$ reductions, occurred when zeolites have been added after MAP precipitation using the MR2. This new material obtained combines good $\mathrm{N}$ and $\mathrm{P}$ concentration and have therefore potentialities to be a high-quality slow-release fertilizer. 